\title{
Reconsider B-vitamins play a vital role in maintaining good health and well-being
}

\author{
Hua Gao-Balch Y* \\ Department of Human Science, the University of Arkansas at Pine Bluff, 1200 North University Drive, Pine Bluff, Arkansas 71601, USA
}

\begin{abstract}
This review is to provide the information to alert of the vitamin B-group of dietary intake should be reconsidered, discussing the potential deficiency factors of vitamin $\mathrm{B}$-group and some ideas about promoting human health and prevention of the disease.
\end{abstract}

\section{Background}

The medicinal condition of a heart attack; a stroke is a lack of oxygen, refer to the blood vessel blocks of the delivery of oxygen-rich blood to critical tissues [1]. Blood is a vehicle to carry oxygen, as we know. Therefore, it is essential to make more red blood cells or generating new blood vessels to carry on oxygen to critical issues. Vitamin B-group has recognized the essential ingredients to produce red blood cells to carry the oxygen to deliver it to body tissues as needs [2]. Vitamin B-group of nutrients helps to plan the optimal balance diet for promoting human health and prevention of the disease. This review is to provide the information related to the vitamin B-group of function and cause of deficiency and dietary of the resource. The goal is to alert of vitamin B-Group of dietary intake of play a vital role in our daily function.

\section{Thiamine (vitamin B1)}

Vitamin B1 is one of the chemical ingredients of the Pyruvate Dehydrogenase Complex, as cofactors thiamine pyrophosphate (TPP) with magnesium to assists in macronutrient metabolism [3]. There are specific pathologies associated with vitamin B1 deficiency, for example, a neurological problem with a cognitive deficit, and encephalopathy [4]. There are various interactions between the nervous system and the immune system; besides, deficiency in vitamins B1 has linked to depression [5]. In classical, Wernicke-Korsakoff syndrome is caused by a lack of intake of Vitamin B1. TPP associated enzymes being dysfunction is called beriberi with prolonged Vitamin B1 of deficiency that can result in the diseases. Dry-beriberi, when you would have a decrease of fluid, which would present with muscle wasting, polyneuritis of condition, is occurring in Partial paralysis from nerve damage. And then there is a wet berry associated with an accumulation of fluid, which would present with a dilated cardiomyopathy as well as edema. Thiamine-responsive megaloblastic anemia (TRMA) syndrome is a rare autosomal recessive disorder and diabetes mellitus, which is related to deficiency Vitamin B1 [6].

\section{Riboflavin (vitamin B2)}

Vitamin B2 has two activity forms of Flavin mononucleotide (FMN), Flavin adenine dinucleotide (FAD), two bio-active vitamin B2 coenzymes are going to be used generally for "Redox", chemistry transferring electrons for energy production to maintain a healthy metabolism [7]. Vitamin B2 is an essential cofactor for glutathione antioxidants, detoxication agents in the liver [8]. Vitamin B2 is responsible for converting folate, niacin, vitamin B6, and vitamin $\mathrm{K}$ into their Active forms [2]. There are specific pathologies associated with vitamin B2 deficiency. A lack of intake of vitamin B2 causes destroys mucosal membranes in the digestive system; inflammation of the mucosa of the mouth and tongue and dermatitis, and symptoms may include cracking on the tongue and at the corners of the mouth [9] Vitamin B2 enhances the absorption of iron; deficiency reduces the mobilization of iron from the store, and low red blood cells or hemoglobin in the blood are associated with the onset of anemia [10]. Deficient of Vitamin B2 is causes cloudy to vision and damage to eye lens called cataracts [11]. Promotes growth and regeneration daily replenishment of vitamin B2 is essential for both growth and matinee individuals. Vitamin B2 intake enhances the activity of enzymes that boost the activation of natural antioxidants present in the body [12]. These antioxidants promote the elimination of free radicals and protect brain cells against damage and death for maintaining proper energy levels [12]. Utilizing oxygen, vitamin B2 converts hydrogen from nutrients into energy. Alcoholics are at particular risk for vitamin B2 of deficiency due to Alcohol's interference with vitamin Metabolism [13].

\section{Vitamin B6 (pyridoxine, pyridoxal, pyridoxine)}

Vitamin B6 of Pyridoxal 5'-phosphate is the metabolically active form. That is involved in cofactor enzymes function to converses the amino acid tryptophan to niacin or the neurotransmitter serotonin [9]. The activation of glycine in the initial stages of heme production needs to the formation of blood to preventing anemia [14]. Vitamin B6 has a function of transamination of amino acids to keto-acids, which can add and remove amino groups in protein and urea metabolism $[15,16]$. Vitamin B6 has decarboxylation of phosphatidylserine to

${ }^{\star}$ Correspondence to: Ying Hua Gao-Balch, Department of Human Science, the University of Arkansas at Pine Bluff, 1200 North University Drive, Pine Bluff, Arkansas 71601, USA, E-mail: gaobalchy@uapb.edu

Key words: coenzyme, b-vitamin, blood, oxygen, bioavailable

Received: August 27, 2019; Accepted: September 17, 2019; Published: September 20, 2019 
phosphatidylethanolamine in phospholipid synthesis, which is then oxidized and used as metabolic fuel for body energy to maintain healthy blood sugar levels, and the nucleic acid formation and lecithin [17]. Vitamin B6 is a cofactor involving side-chain cleavage, including cystathionine synthase and cystathionine. There are specific pathologies associated with vitamin B6 deficiency. Hyper-homocysteinemia is controlling by vitamin B6; high levels of plasma homocysteine are cause cardiovascular risks [18]. Cystathionine is produced by the transculturation pathway, which converts homocysteine into cystathionine, which is cystathionine is an intermediate in the synthesis of cysteine [19]. It is also producing tryptophan a critical the nervous system hormone, and its impacts on tryptophan metabolism to reduce depression by releasing serotonin [20]. Vitamin B6 of Clinically deficiency caused the Carpal Tunnel Syndrome (CTS) [21].

\section{Vitamin B12 (cobalamins)}

Vitamin B12 has the complex absorption mechanisms, Transcobalamin II and trans-cobalamin I responsible for the delivery of vitamin B12 to go peripheral tissues and the liver, respectively [22]. Vitamin B12 functions in folate metabolism and helps to maintain the myelin coating in the body's nervous system [23]. A well-known cause of vitamin B12 insufficiency of pernicious anemia with autoimmune destruction of parietal cells, consequent impairment of intrinsic factor secretion [24]. Vitamin B12 deficiency also occurs from inadequate dietary intake with malnourished of the elderly, and with alcohol excess [25]. A recent systematic review confirmed the link between metformin treatment and low serum cobalamin levels but highlighted that an association between vitamin B12 deficiency and clinical symptoms remains controversial [26]. The deficiency vitamin B12 caused increase serum homocysteine to lead to the risk of development of cardiovascular disease with type 2 diabetes mellitus [27,28]. The most typical cause is food-bound cobalamin malabsorption (FBCM) of medical conditions to lead to decreased secretion of Hydrochloric acid, thereby reducing the liberation of vitamin B12 from food proteins.

\section{Highest bioavailable of nutrients in the foods}

In the above information, Vitamin B-group has a function to assist in neurological function, produced healthy red blood, and energy metabolism in the cells to assure our optimal daily activity. Good news to most of the people with Vitamin B-group of the deficiency is preventable. In our lives, more than anything else, the foods we eat daily help determine whether to be healthy or not or remain healthy into older age. There are many of the highest bioavailable of vitamin B-group of nutrients in the foods. American of the Institute of Medicine of The National Academies has developed a guide for the vitamin B-group intake on a scientific basis; it is called Dietary Reference Intake (DRI). Table 1 Summarize DRI of recommended intake Vitamin B-group for the men, women, and highest bioavailable of nutrients in

Table 1. DRI of recommended intake Vitamin B-group for the men, women, and highest bioavailable of nutrients in the foods

\begin{tabular}{|l|c|c|c|}
\hline VitaminB1 & $1.2 \mathrm{mg} /$ day & $1.1 \mathrm{mg} /$ day & $\begin{array}{c}\text { Pork loin, beans, sweet potato, sunflowers. } \\
\text { fortified bread }\end{array}$ \\
\hline VitaminB2 & $1.3 \mathrm{mg} /$ day & $1.1 \mathrm{mg} /$ day & $\begin{array}{c}\text { Beef of liver. Mushrooms, pork chops, } \\
\text { spinach, Fortified bread }\end{array}$ \\
\hline VitaminB6 & $1.3 \mathrm{mh} /$ day & $1.3 \mathrm{mg} /$ day & $\begin{array}{c}\text { Beef liver, pork loin, organ meats. } \\
\text { Fortified bread }\end{array}$ \\
\hline VitaminB12 & $\begin{array}{c}2.4 \\
\text { micrograms/ } \\
\text { day }\end{array}$ & $\begin{array}{c}2.4 \text { micrograms/ } \\
\text { day }\end{array}$ & $\begin{array}{c}\text { Lamb, Pork of Rabbit. Goose of smoked. } \\
\text { Oysters. Mussel }\end{array}$ \\
\hline
\end{tabular}

(Adapted from McGuire M, Beerman K (2018) Table of food composition for nutritional sciences. www.cengage.com/wadsworth) the foods. Vitamin B1, 2 require an increase with an excessive intake of carbohydrates. The vitamin B6 obtained from animal foods and fortified foods tend to be better absorbed than that obtained from plant foods. About $75 \%$ of vitamin B6 from a mixed diet is bioavailable. There is not present Vitamin B12 within the plant of foods. In the market sale, the fortified with vitamin B12 breakfast cereals with high bioavailable for vegetarians, there are fortified foods with vitamin B12 vary in the formulation. Vitamin B-group is a vitamin of a water-soluble the body well regulates that; thus, an overdose is rare to happen and usually only occur with vitamin B injections or supplements.

\section{Conclusion}

Vitamin B-group is interaction with our body chemistry, a hormone to maintain our body for optimal function. However, how much is enough? Our body changes may correlate with we intake vitamin B-group, all of which discussed herein. We need to study the matter furthermore in nutrients reference intake to provide the most useful science basics of information to the people.

\section{References}

1. Amy G, Hofmann (2010) Perfusion vs. oxygen delivery in transfusion with "fresh" and "old" red blood cells: The experimental evidence. Transfusion and Apheresis Science 43: 69-78. [Crossref]

2. Kennedy DO (2016) B Vitamins and the brain: mechanisms, dose and efficacy--A review. Nutrients 8: 68. [Crossref]

3. Suzuki M, Itokawa Y (1996) Effects of thiamine supplementation on exercise-induced fatigue. Metabolic brain disease 11: 95-106. [Crossref]

4. Kumar N (2010). Neurologic presentations of nutritional deficiencies. Neurological Clinical 28: 107-170. [Crossref]

5. Mikkelsen K, Stojanovska L, Prakash M, Apostolopoulos V (2017) The effects of vitamin $\mathrm{B}$ on the immune/cytokine network and their involvement in depression. Maturitas 96: 58-71. [Crossref]

6. Oishi K, Diaz GA (2019) Thiamine-responsive megaloblastic anemia syndrome. US national library of medicine national institutes of health. In: Adam MP, Ardinger HH, Pagon RA, Wallace SE, Bean LJH, et al. (eds)

7. Teufel R, Agarwal V, Moore S (2016) Unusual flavoenzyme catalysis in marine bacteria. Current Opinion in Chemical Biology 31: 31-39. [Crossref]

8. Ashoori M, Saedisomeolia (2014) A Riboflavin (vitamin $\mathrm{B}_{2}$ ) and oxidative stress: a review. British Journal of Nutrition 111: 1985-1991. [Crossref]

9. Brody T (1999) Nutritional biochemistry. San Diego: Academic press

10. Agte V, Paknikar, M Chiplonkar A (1998) Effect of riboflavin supplementation on zinc and iron absorption and growth performance in mice. Biol Trace Elem Res 65: 109-115.

11. Mastropasqua L (2015) Collagen cross-linking: when and how? A review of the state of the art of the technique and new perspectives. Eye Vis (Lond) 2: 19. [Crossref]

12. Ashoori M, Saedisomeolia A (2014) Riboflavin (vitamin B2) and oxidative stress: a review. Published online by Cambridge university press.

13. Mirzakulova E, Khatmullin R, Walpita J, Corrigan T, Vargas-Barbosa M, et al. (2012) Electrode-assisted catalytic water oxidation by a flavin derivative. Nature Chemistry 4: 794-801.

14. Yostina Farid Y, Lecat P (2019) Biochemistry, hemoglobin synthesis. Stat Pearls.

15. Sieniawska E, Baj T, Sawicki R, Wanat A, Wojtanowski KK, et al. (2017) LC-QTOFMS analysis and activity profiles of popular antioxidant dietary supplements in terms of quality control. Oxid Med Cell Longev 2017: 8692516. [Crossref]

16. Berg M, Tymoczko L, Stryer L (2002) Biochemistry. 5th ed. New York: W H Freeman. The first Step in amino acid degradation is the removal of nitrogen.

17. Delorme CB, Lupien PJ (1976) The effect of vitamin B-6 deficiency on the fatty acid composition of the major phospholipids in the rat. J Nutr 106: 169-180. [Crossref]

18. Zhang DM, Ye JX, Mu JS, Cui XP (2017) Efficacy of vitamin b supplementation on cognition in elderly patients with cognitive-related diseases. $J$ Geriatr Psychiatry Neurol 30: 50-59. [Crossref] 
19. Ripps H, Shen W (2012) Review: taurine: a "very essential" amino acid. Mol Vis 18: 2673-2686. [Crossref]

20. Schaeffer M, Gretz D (1998) Dietary excess of vitamin b-6 affects the concentrations of amino acids in the caudate nucleus and serum and the binding properties of serotonin receptors in the brain cortex of rats. American Society For Nutritional Sciences 98: 1829-1835.

21. Talebi M, Andalib S (2013) Effect of vitamin b6 on clinical symptoms and electrodiagnostic results of patients with carpal tunnel syndrome. Advanced Pharm Bull 3: 283-288

22. Obeid R (2019) Vitamin B12 Intake from Animal Foods, Biomarkers, and Health Aspects. Journal of Front. Nutrition 28: 6: 93. [Crossref]

23. Reynolds E (2006) Vitamin B12, folic acid, and the nervous system. Lancet Neurol 5: 949-960. [Crossref]
24. Carmel R (2011) Biomarkers of cobalamin (vitamin B-12) status in the epidemiologic setting: a critical overview of context, applications, and performance characteristics of cobalamin, methylmalonic acid, and holotranscobalamin II. American journal clinical nutrition.

25. Droogsma E, van Asselt D, De Deyn PP (2015) Weight loss and undernutrition in community-dwelling patients with Alzheimer's dementia: From population based studies to clinical management. Z Gerontol Geriatr 48: 318-324. [Crossref]

26. Liu Q, Li S, Quan H, Li J (2014) Vitamin B12 status in metformin treated patients: systematic review. PLoS One 9: e100379. [Crossref]

27. Brattström L, Wilcken D (2000) Homocysteine and cardiovascular disease: cause or effect? The American Journal of Clinical Nutrition 72: 315 -323.

28. Tinelli C, Pino A, Ficulle E, Marcelli S (2019) Hyperhomocysteinemia as a risk factor and potential nutraceutical target for certain pathologies. Front Nutrition 6: 49.

Copyright: (2019 Hua Gao-Balch Y. This is an open-access article distributed under the terms of the Creative Commons Attribution License, which permits unrestricted use, distribution, and reproduction in any medium, provided the original author and source are credited. 